\title{
Experiences of Student Nurses on the Use of the Two-Week Block System at the Satellite Campus of a Higher Education Institution in Namibia
}

\author{
Gelasius Panduleni Shatimwene ${ }^{1}$, Daniel Opotamutale Ashipala ${ }^{1} \&$ Esther Kamenye $^{1}$ \\ 1. Department of General Nursing Science, School of Nursing, Faculty of Health Sciences, University of Namibia \\ (UNAM), Rundu, Namibia \\ Correspondence: Mr Daniel Opotamutale Ashipala (Senior Lecturer), Department of General Nursing Science, \\ School of Nursing, Faculty of Health Sciences, University of Namibia (UNAM), PO Box 88, Kaisosi Road, Rundu, \\ Namibia. \\ E-mail: dashipala@unam.na. ORCiD (Daniel Opotamutale Ashipala iD): https://orcid.org/0000-0002-8913-056x
}

Received: March 19, 2020

doi:10.5430/ijhe.v9n3p222
Accepted: April 1, 2020

Online Published: April 2, 2020

\begin{abstract}
Clinical Training is intended to prepare nursing students for future nursing practice in both private and public facilities. As do many nursing training institutions globally, this Higher Education Institution (HEI) uses the two-week block system as a teaching system. However, despite the two-week block system, it would appear that, due to the increased number of nursing students, the aligning of practical exposure with theoretical instruction is becoming difficult in balancing theory and practice for both student and academics. Such alignment requires institutions of higher learning to establish which teaching systems are likely to promote the correlation between theory and practice. The experiences of students may be used to identify positive learning environment for students. This study aimed to explore and understand the personal experiences of student nurses studying at HEI in Namibia in relation to the use of the two-week block system. The objectives of the study included exploring and describing the experiences of student nurses regarding the two-week block system at the HEI with a view to ascertaining the negative impact, if any, of such a teaching system on their studies. A study employed a qualitative approach which comprised an explorative and descriptive research design, using purposive sampling. The research population in the study consisted of first to fourth year, undergraduate nursing students who were studying at a satellite campus of a HEI in Namibia. The requisite data was collected from four focus group discussions which were each conducted with six to seven participants. The transcribed interviews and narratives from the research notes were then organised into main themes and sub-themes. Three main themes and nine sub-themes were identified. The findings of the study indicated that two-week block system was associated with challenges as was evidenced by the following themes that had emerged from the study, namely, different experiences of the two-week block system, various effects of the two-week block system and recommendations to School of Nursing (SoN).

The study recommended that the HEI extend the two-week block system to a one-month block system in order to give the students sufficient time in which to put the theory they have learnt into practice.
\end{abstract}

Keywords: experiences, student Nurses, block system, two weeks, higher education institution

\section{Introduction}

Nursing is a practice-based profession and, thus, clinical practice is central to nursing education. Such clinical practice enhances the opportunities for the students to develop both confidence and competence (Ngaiyaye, Bvumbwe, \& Chipeta, 2017). According to Kabanya, Karani and Mirie (2017), during block teaching students learn theory for a block of two to four weeks, followed by a clinical area placement for a period of two to four weeks. The training of nurses is crucial worldwide as nurses are the mainstay of the health care services which are tasked with promoting the health of individuals in the community (Nuuyoma \& Ashipala, 2018). A nurse is engaged in the practice of the health care of a human prior to birth until the end of life. Thus, nurses are men and women whose main responsibilities are to maintain the health of individuals, providing health education to healthy individuals on disease prevention; treat the sick by providing them with treatment; and help those suffering from chronic conditions to cope better with their conditions in the form of rehabilitation. It is, therefore, vital that nurses receive proper and 
appropriate training to enable them to fulfil their responsibilities to their patients effectively. If a country is to have a healthy nation, well trained nurses are required (Nuuyoma \& Ashipala, 2018).

In order to qualify as a professional nurse, the person must undergo three to four years comprehensive training (Nursing Act, no 8 of 2004). During that training period, the student nurse is given both practical and theoretical training. A nurse should receive training in anatomy and physiology and write tests at the HEI, before being allowed to go to the health facility to execute practical procedures such as administering injections to patients.

It appears that the curriculum for teaching student nurses should consider the balance between theory and practice (Dimitriadou, Papastavrou, Efstathiou, \& Theodorou, 2015). In some HEI, student nurses are being trained using three-month, two-week or two-day block systems. The block system depends on the curriculum framework adopted by a HEI. During the theory period where students spend time in the classroom), students also use simulation rooms in order to learn how to use equipment and devices before using them on actual patients in the clinical setting (Landers, 2018). This is also done to ensure that students do not struggle with equipment and devices in front of the patients which may result in the patients losing confidence in the student nurses (Dimitriadou et al., 2015).

According to Birks, Bagley, Park, Burkot, and Mills (2017), it is essential that nursing education provides students with a comprehensive knowledge base to support the critical thinking and clinical decision-making characteristic of expert practice. The undergraduate nursing students are given a theoretical foundation and offered opportunities to practise skills in a simulated environment before they are sent to clinical areas during their studies. This takes the form of either a block or distributed system or both.

According to Mellish, Brink, and Paton (2016), one of the benefits of using a block system was that students were not exposed to the stresses of the ward situation. In order for the block system to be successful it is essential that, when students are away from the classroom, they correlate theory and practical; the clinical instructors, ward personnel and nurse educators continue the theoretical instruction and the student perform compulsory projects or assignment work throughout the two weeks in practical area (Bruce, Klopper, \& Mellish, 2019). At the time of this study there was no evidence of another study which had been conducted in Namibia on the experiences of nursing students in a two-week block system. The practice of placing students in a two-week block system was introduced in 2017 in a satellite campus, and it was felt by the researcher that this warranted a study to explore their experiences in respect of block teaching during its infancy.

Training is a tool which is intended to prepare nursing students for future nursing practice in both private and public facilities. Nursing students are equipped with the knowledge, skills and correct attitudes they require to enable them to perform nursing care with dedication, compassion and as per their scope of practice (MoHSS, 2010). In order to achieve this, the HEI satellite campus decided to utilise the block delivery system. This system allocates a specified time to nursing students receiving fulltime theoretical instruction at the training institution and also some time for clinical practice (Bruce et al., 2019). However, the recent escalation in the number of student enrolling in the training institutions has led to an increased workload for the lecturers as they endeavoured to meet the requirements of their teaching and administrative work (Ngaiyaye et al., 2017). The increased number of nursing students also meant that aligning practical exposure with theoretical instruction had become difficult for academics, which had a negative impact on the students (Birks et al., 2017).

Within a month, on-campus students spend two weeks on clinical practice and are then allocated to theoretical instruction for two weeks. During the two weeks of on-campus theory in a month, student nurses are required to attend simulation sessions; attend theoretical lectures for seven modules; write tests for each module, complete assignments and participate in group work, as well as presenting class individually or in a group. Despite the fact that the block system has been implemented at the time of the study it was not, clear whether the system was balancing theory and practice, and whether the system was allocating sufficient time for studying, given that the campus was new with limited resources. It would appear that the students were busy with numerous activities scheduled in a two week including an intensive theory timetable and simulation sessions. As the HEI satellite campus, the lecturers, and the student nurses were new, there appeared to be little or no idea how the student nurses were experiencing the two-week block teaching system.

Accordingly, the following research questions were posed:

- What are the experiences of student nurses in relation to the two-week block system at the HEI in Namibia?

- What recommendations may be made to inform the HEI, specifically the School of Nursing on ways in which to improve the system? 


\section{Research Design and Methods}

Research Design

This study utilised a qualitative explorative, descriptive and research contextual design (Creswell, 2014) in order to gain an in-depth understanding of the experiences of undergraduate student nurses in relation to the two-week block system at the HEI in Namibia. According to Maree (2016), a qualitative research design is naturalistic as it focuses on the natural settings where interactions occur. In addition, it is also a design which used to explore the way in which people make sense of their surroundings, experiences and understanding of phenomena (Green \& Thorogood, 2018).

\subsection{Context of the Study}

This study was conducted on the HEI in Namibia public university campus in the north-eastern region of Namibia a newly established satellite campus that offers student nurses training to enable them to become professional nurses. The campus offers courses in education, nursing science and management sciences. This study focused only on the undergraduate student nurses registered for the Bachelor of Nursing Science (Clinical) (Honours) as this was the only programme on the campus using the two-week block system at the time of the study. The School of Nursing (SoN) at the satellite campus was established in 2017 and offers one nursing programme only, namely, a Bachelor of Nursing Science (Clinical) (Honours). The higher education institution is deemed as the main HEI involved in the training of nurses to become professional nurses, and were using the two-week block system at the time of this study. According to the HEI satellite Campus records, there were 305 students studying towards a Bachelor of Nursing Science (Honours) (Clinical) in 2019. At the time of the study, the School of Nursing was alternating the first, second, third and fourth-year students on a two-week block system: the first and third years spent two weeks in the classroom, then the second and fourth years spent two weeks on clinical practice.

\subsection{Participants and Sampling}

The population for this study consisted of four cohorts of 305 undergraduate nursing students registered at the HEI satellite Campus, namely, first, to fourth year students studying towards a Bachelor of Nursing Science (Clinical) (Honours). The sample in this study comprised all undergraduate student nurses studying fulltime on the HEI satellite Campus in 2019. Sampling refers to the process of selecting a portion of the population of interest to represent the whole population (Polit \& Beck, 2016). The researcher approached participants face-to-face in the classroom on the HEI campus and explained the purpose and objectives of the study to them. A purposeful sampling (convenient) technique was used to draw a sample of $25(\mathrm{n}=25)$ readily available students from a total of 305 students registered on the campus (Brink, Van der Walt, \& Van Rensburg, 2018).

\subsection{Data Collection Procedures}

The data for this study was collected between October and November 2019 using a focus group discussion. The students who were willing to participate in the study were recruited by the researcher and the time and venue for the focus discussion group were arranged with them. A total of four focus group discussions, each consisting of six to seven participants, were conducted. The discussions lasted about 30 to 55 minutes while the number of discussions held was determined by data saturation (Polit \& Beck, 2018). The focus group discussions were framed by semi-structured questions to enable the researcher both to gain an informed understanding of the participants' lived experiences and to increase the credibility of the findings (Creswell \& Creswell 2018). The researcher used a semi-structured focus group interview guide, with a topic guide which had been prepared and written prior to the discussions. Probing questions were also used to further explore the participants' responses and to stimulate the gathering of more detailed information than may otherwise have been the case (Polit \& Beck, 2018). Research questions that were used in the study included: 1 . What is your experiences regarding the use of two-week block system? 2. How does the two weeks block system affect your academic performance as a nursing student? 3 . What are your recommendations to the SoN on how to improve the use of two weeks block system? All interviews were audio recorded with the participants 'permissions. Field notes were also used by the researchers to record non-verbal cues. At the end of the discussion, member checking was conducted to confirm with the participants whether what was recorded was a true reflection of their challenges. Data saturation was also reached at the end of the second focus group discussion.

\subsection{Data Analysis}

Content analysis was used to analyse the data attained from the participants (Burns \& Grooves, 2013). In addition to field notes, data obtained from the focus group interviews were transcribed in verbatim and coded by the researchers. A list of all similar codes were grouped together to form categories and then themes. 


\subsection{Quality Measures}

Strategies for ensuring trustworthiness of data in this study were ensued through the use of the Lincoln \& Guba's (1985) criteria: credibility, transferability, dependability and confirmability. Credibility was ensured by prolonged exposure with participants and member debriefing made soon after data collection, which ensured that the participants could view transcripts of the interviews to verify whether they were a true reflection of what they had given during the interview. Transferability was ensured by collecting data up to saturation point. In addition, the researchers provided detailed descriptions of the results. Dependability in this study was enhanced by providing a dense description of the research methods used and its implementation, as well as by describing the steps that were taken to collect data and how the data was analysed. Confirmability was ensured by discussing the research process and findings with peers, with the researchers maintaining reflexivity by writing down their perceptions and beliefs so they would not influence findings and decisions made in the study.

\subsection{Ethical Considerations}

The research proposal for this study was submitted to the Ethics and Research Committee of the HEI for ethical approval that was granted. The researcher obtained the participants' personal consent in relation to their participation in the study after the purpose and significance of the study had been explained to them. Ethical principles were adhered to throughout the study in order to protect the rights, dignity and safety of the participants (Grove et al., 2013, p. 171). Participation in the study was voluntary and the participants were free to withdraw from the interviews at any time if they so wished (Creswell, 2014, p. 11). It is not possible in qualitative research to completely guarantee anonymity because such research involves direct contact with the participants. However, the researcher assured the participants that their participants would not be disclosed and that no names of the participants would be linked to the data. In addition, confidentiality was ensured as the participants were each given numerical codes at the beginning of the structured interviews which were then used to represent the names of participants during the interviews and which subsequently appeared in the transcript of the interview to ensure their anonymity (Grove et al., 2013, p. 171).

\section{Findings}

\subsection{Description of Participants}

Twenty-five (25) nursing students of the Bachelor of Nursing Science degree programme participated in the study. The participants consisted of six first years, six second years, seven third years and six fourth nursing students in their level of study. There were $13(52 \%)$ female participants and $12(48 \%)$ males. All participants were under the age of 40

\subsection{Presentation of Findings}

Three themes emerged from the challenges experienced by nursing students regarding the use of two-week block teaching. The themes are outlined below.

The themes and sub-themes which emerged from data analysis are presented in the table below

Table 1. Themes and sub-themes which emerged from the data analysis

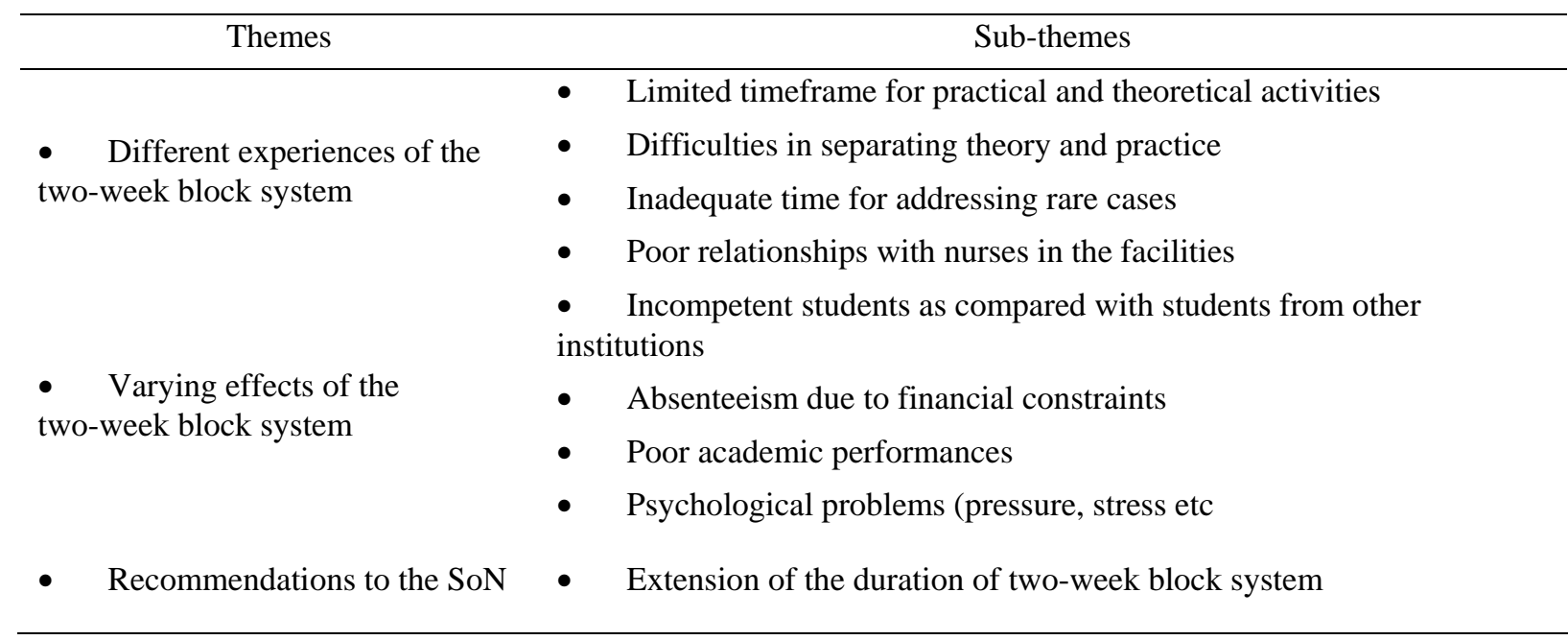




\subsection{Theme One: Different Experiences of the Two-week Block System}

This theme reflects the students' experiences relating to the two-week block system which is in use at the HEI at the time of the study. The sub-themes which emerged from the discussions with the participants include limited timeframe for practical and theoretical activities, difficulties in separating theory and practice, inadequate time for addressing rare cases and poor relationships with nurses in the facilities.

\subsubsection{Limited Timeframe for Practical and Theoretical Activities}

The participants expressed the view that the two-week block system was too short and did not give the students sufficient time in which to learn and practise the required activities as much as possible. This is confirmed in the extracts quoted below.

When you are about to get used to the activities and procedures in the ward, that's the time you are going out because in the first week you have to get oriented in the place in which you are working and in the second week you are trying to do the job in the correct manner, and the timeframe is just too short to learn everything in five days ( $\mathrm{P} 2 \mathrm{G} 2)$.

Being put there just for two weeks, for instance, in theatre, you usually learn nothing from it. By the time you want to get involved in the practical aspect of the training, two weeks are over and you are out (P5G2).

Some of the participants also indicated that two-week block system did not allow them time to study for their tests and complete their assignments, and they were forced to memorise things in order to pass instead of studying in order to understand the work.

You find that you have three assessments, like tests, in a week so, instead of your learning, you are memorising, so you don't study to know, you only study to pass (P3G2).

Some of the participants highlighted that they always found it difficult to complete their practical work books in the two-week block system because some procedures are carried out only in certain departments and they are only allocated at each department once for two weeks. They added that, in addition, this system resulted in their having to be absent from classes at times as they had to go back to the wards so that they could finish their practical books in order to qualify for the examinations.

Most of us end up having books that are not done and now we have to find our own ways or time to go back to the wards but then, at the same time, we have to be at theory classes (P6G2).

\subsubsection{Difficulties in Separating Theory and Practice}

The students raised their concern that they sometimes failed to differentiate between theoretical time and practical time because they were required to do practical components while busy with theory or do theoretical components while busy with practical work.

\section{It disturbs time because you are at practical, then you are called to do theory on campus (P4G2).}

We are overloaded with work, especially the theory part because the two weeks that you are there you do not relax as you are still doing practical and theoretical work and you still have assignments to do (P4G3).

\subsubsection{Inadequate Time for Addressing Rare Cases}

Some students highlighted their concerns about their knowledge about certain rare procedures carried out at the clinical facilities. They emphasised that, due to the limited time in the clinical areas, they felt they did not receive adequate exposure to the procedures that were sometimes carried out only once or twice in the two-week block period.

You find yourself in the ward and you need to put up a blood transfusion, you may go out of the ward or maybe you end up in fourth year and you cannot even put up a blood transfusion on your own because these are rare cases that can only occur once or twice in two weeks (P3G2).

Sometimes you end up with an incomplete practical book because sometimes you want to demonstrate a procedure but once you start, the nurse will stop you, telling you that you do not know. This is because of the adequate exposure to that particular procedure (P6G2).

\subsubsection{Poor Relationship with Other Nurses}

Some of the participants expressed the view that two-week block system had a negative effect on their opportunities to establish good, strong relationships with the nurses in the wards. They cited the example of students from other 
institutions who do practical work for one month and are able to establish good, strong relationships with the nurses in the wards or at the clinics, unlike these specific HEI students who stay for two weeks only.

Most HEI students complain that nurses favour training centre students, but training centre students have more time in which to create relationships with the nurses in the wards because they stay do practical work for at least a month but we are there only for two weeks so we are withdrawn and the next time you are in different ward and you are meeting new sisters again. It is just too little time in which to establish a relationship or to get to know the sisters better which could help the students to feel comfortable in the wards (P4G2).

A relationship is very important and us we don't have a relationship with the nurses on the ground because of the limited time. That aspect is very important ( $\mathrm{P} 5 \mathrm{G} 2)$.

\subsection{Theme Two: Various Effects of the Two-week Block System}

The participants highlighted various effects of the two-week block system on the nursing students at the HEI in Namibia. The sub-themes that emerged included incompetent students in comparison with students from other institutions, absenteeism due to financial constraints, poor academic performances and psychological issues, such as stress.

\subsubsection{Incompetent Students in Comparison with Students from Other Institutions}

Most of the participants indicated that they lacked competence as compared to students from other institutions who were placed in clinical areas for a month, unlike the students from this HEI who were placed there for two weeks only. They cited the inadequate timeframe for them to learn and become competent was shorter as compared to the students from other institutions.

If I have to compare us with students from other institutions who normally have practical for one month, those students are actually more competent than we are (P1G2).

One participant believed that the more time one has to practise the more time one has to learn.

If you stay in the ward for a month, I guarantee that you will be able to perform much better than if you in the ward for only two weeks (P3G2).

Some students highlighted that the lack of consistency at the clinical areas as one of the factors contributing to the incompetency of the HEI nursing students.

Consistency is the thing which matters in learning, especially skills. When there is consistency you are there for longer or exposed for longer time. You are doing a routine or procedure now and then, so those things come automatically to you (P5G2).

\subsubsection{Absenteeism Due to Financial Constraints}

Most students highlighted that some students absented themselves from the practical work because of a lack of transport money.

When you get a month allocation, you will go there at the beginning of the month when parents have money or the month will end while you are on practical, meaning parents have time to get the money for you to go to the practical work (P6G2).

Sometimes you find yourself going for practical in the middle of the month and your parents are really find it difficult to give you transport money. There is no money for transport (P6G2).

\subsubsection{Poor Academic Performances}

The participants noted that in two weeks that they are at theory classes, they were taught too much content for them to absorb and, as a result, they were often not able to concentrate in the class with this resulting in poor academic performances on their part.

We are taught things that are too much for our brains and you cannot concentrate anymore in class (P6G2).

One participant highlighted that, due to extensive content in all the modules and taught within a short space of time, sometimes they did not have sufficient time in which to revise what they had been taught in class because they were sometimes given tests in all the modules. This often resulted in poor academic performance.

We are just under pressure and you don't even have time to read what you were tanght yesterday, instead, you read for the test and forget other things (P6G2). 


\subsubsection{Psychological Issues Including Pressure and Stress}

The participants indicated that the two-week block system meant they had to do everything in a rush which increased the pressure on them. This often meant they became stressed with this stress having an adverse psychological effect on them. They added that they went through a lot and they felt that they needed psychological support from their lecturers. However, it appeared that the lecturers were failing to provide them with psychological support.

You know we are different and we are affected differently, so we also need psychological help from our lecturers to encourage us because these things are just too much to handle (P6G2).

We do everything in a rush in two weeks and, with the rush comes, pressure, and, with pressure, comes stress and this is where you might find that you are not prepared and your performance drops (P2G2).

One participant stated that being taught so much content within a short period of time resulted in students working extremely hard and becoming tired. As a result, they were not having enough sleep and this was adversely affecting their ability to improve their academic performance with this leading to a build-up pressure and stress.

The pressure is just building up and, whenever you have pressure, you are psychologically affected (P3G2).

\subsection{Theme Three: Recommendations to the SoN}

This theme emerged from the participants' responses when they asked to express their opinions on what could be done to improve the block system that was in existence at the time of the study. The participants suggested an extension to the duration of the two-week block system.

\subsubsection{Extension of the Duration of the Two-week Block System}

When asked about what could be done to improve the existing block system, the majority of the participants suggested that the two-weak block system be extended to a one-month block system.

They should just extend the two-weak block system to a month, that's actually my recommendation (P1G2).

The participants believed that a one-month block system would improve both the theoretical and the practical performance of the students because it would allow the students sufficient time in which to learn at their own pace with a relaxed mind.

I think they should increase it to a month because there will be more time to learn (P6G2).

I am in support of the extension of the two-weak block system to a month because that will give more the students more time in which to study and I hope and believe that the lecturers will also have time in which to assist students in a way that will be helpful (P3G2).

\section{Discussion of Findings}

The purpose of the study was to explore and understand the experiences of nursing students in respect of the two-week block system used at the HEI satellite Campus, and this section presents a discussion of the findings of the study.

\subsection{Different Experiences on Two-week Block System}

The study found that the two-week block system was too short and it did not give students adequate time in which to learn and practise the required activities as much as possible. These findings were similar to those of Birk et al. (2017) who reported that one to two-week block did not provide adequate time for nursing students to settle into the clinical settings and that this affects their experiences. This study also revealed that the students sometimes failed to differentiate between the theoretical component and the practical component because they were at times required to do the practical components while busy with theory or the theoretical components while busy with the practical work. The findings from this study were in line with those of Bruce et al. (2019) who indicated that, while students are busy with either the theoretical or practical block, they have to continue doing their compulsory projects or assignments work throughout from blocks.

The participants in this study highlighted their concerns about their lack of knowledge of some rare procedures carried out at the clinical facilities. They emphasised that, due to the limited time in the clinical areas, they felt they did not receive adequate exposure to the procedures that sometimes occurred once or twice only in the two-week period. Salifu, Gross, Salifu and Jerry (2019) also indicated that students were of the view that a time period of two weeks allocated to clinical placement was too short to allow them follow interesting clinical cases as well as to promote clinical learning because some students went to the hospitals without knowing what would be expected of them and, thus, the first week of placement was often not productive. Salifu et al. (2019) further emphasised that 
going to the hospital for one week is not sufficient at all because when the students encounter a client or patient suffering from an interesting condition they are not able to follow it because the following week they are back in class for theory. Some of the participants expressed the view that two-week block system was impeding their chances of establishing good, strong relationship with the nurses in the wards. This aligned with Birk et al. (2017) who stated that a longer period of placement would enable students to develop effective communication skills and to become familiar with the staff and routines on the wards.

\subsection{Various Effects of the Two-week Block System}

Most of the participants in this study felt that the nursing students from the HEI lacked competence as compared to students from other institutions such as the National Health Training Centre and the Welwitchia Health Training Centre who were placed in clinical areas for a month, unlike the higher education institution students who placed there for two weeks. They expressed the view that the timeframe they had in which to learn and become competent was shorter than that of the other students. Francis (2012) indicated that the duration of clinical placement is regarded as a mechanism to enable for students to achieve competency and that it appeared that those graduates who had been exposed to longer durations of clinical placement demonstrated a higher quality of patient care. Sufficient time allocation in clinical areas helps nursing students to develop both competence and confidence in relation to clinical procedures (Rajeswaran, 2016).

The participants highlighted that some students absented themselves from the practical work due to a lack of transport money. They also noted that, in the two weeks that the students spend in theory classes, they were being taught too much content for their brains to absorb and, as a result, were not able to concentrate in class with this, in turn, resulting in poor academic performances. Bruce et al. (2019) noted that long hours of continuous lectures may produce poor learning if the activities are not broken up while Vanson and Beckett (2018), who reported on one-week block teaching, also indicated that the learning by the student would be adversely affected as too many topics are covered in a short period of time.

The participants explained that the two-week block system resulted in the students having to do everything in a rush which increased the pressure on them. When they had to do everything in a rush and within a short period of time, they became stress and were psychologically affected. They added that they had to go through a lot and they felt that they needed psychological support from their lecturers but that the lecturers were failing to provide them with such support. Francis' (2012) report supported the finding that a short period of clinical placement is likely to increase the students' level of tension and anxiety and may also diminish their opportunities to construct their own level of knowledge. It was clear that the two-week block teaching was having a negative impact on the students' learning as the short period of time allocated to the clinical areas was creating fears about making mistakes and harming patients, as well as worries about the academic workload (Rajeswaran, 2016).

\subsection{Recommendations to the SoN}

The majority of the participants in the study were of the view that the extension of the two-week block system to a one-month block system would improve both the academic and practical performance of the students, and it would enhance the competence of the HEI nursing students. Birk et al. (2017) report suggested that a longer period of placement helps students to integrate theory and practice more effectively because they have sufficient opportunities to explore in detail what they have encountered in the wards. Francis's (2012) report suggested that ensuring an appropriate period of time for students to acquire the skills and knowledge required to register as a competent professional nurse. It was further stated that a prolonged duration of clinical placement would result in a pattern where the extent of nursing practice would be wider than it may otherwise have been and improve the preparation of the students.

\section{Limitations of the Study}

The results of this study were obtained only from one satellite campus of the HEI that is making use of local public hospitals for clinical practice. It was thereby not possible to generalise the results of this study to other campuses in the country. In addition, there appeared to be limited literature on the experiences of nursing students in relation to the two-week block system. In addition, the researcher experienced challenges in the recruitment of the research participants. Although there were three faculties on the satellite Campus this study focused only on first to fourth year nursing students from the Faculty of Health Sciences, School of Nursing. 


\section{Implications for the University}

The focus group discussions revealed that the majority of the nursing students shared negative experiences and challenges in relation to the two-week block system. Accordingly, the study highlighted certain recommendations and suggestions that may improve the existing block system.

\section{Recommendations}

Based on the information discussed above the following recommendations were made:

The two-week block system should be extended to at least a one-month block system. Students should be provided with practical books during the initial clinical placement. Lecturers should make an effort to orientate the students on the practical books as early as possible. Students should be introduced to fundamental procedures before they are sent to clinical practice facilities to enable them to execute the clinical procedures and practical outcomes with ease.

\section{Conclusion}

The findings of this study led to the conclusion that two-week block system was too short and that it did not give the students adequate time in which to learn and apply the theory they have been taught to practice. The results also revealed that students were finding it difficult to complete their practical books in two-week and that the two-week block system was having a negative impact on the academic performances and psychological wellbeing of the students. Based on these results, a call is made for well-articulated plans and actions to address the challenges associated with the two-week block system.

\section{Acknowledgements}

The researchers are grateful to the School of Nursing Research Committee, Faculty of Health Sciences and the HEI satellite Campus for granting permission to conduct the study on their premises and using their students. The researchers would also like to thank all the participants who took time to take part in the study as well as the supervisor for his assistance and support during the manuscript writing process. Without their participation and support, this study would not have been possible.

\section{References}

Barrow, J., \& Khandha, P. (2019). Research ethics. Treasure Island: StatPearls Publishing.

Birks, M., Bagley, T., Park, T., Burkot, C., \& Mills, J. (2017). The impact of clinical placement model on learning in nursing: A descriptive exploratory study. Australian Journal of Advanced Nursing, 34(3), 16-23.

Brink, H., Van der Walt, C., \& Van Rensberg, G. (2018). Fundamentals of research methodology for healthcare professionals (3rd ed.). Cape Town: Juta.

Bruce, C., Klopper, C., \& Mellish, M. (2019). Teaching and learning the practice of nursing. Cape Town: Heinemann.

Creswell, J. (2013). Qualitative inquiry \& research design: Choosing among five approaches (3rd ed.). Los Angeles: SAGE Publications.

Creswell, J. W. (2014). Research design: Qualitative and quantitative approaches (2nd ed.). Thousand Oaks, CA: Sage Publications.

Creswell, J. W., \& Creswell, D. J. (2018). Research design: Qualitative, quantitative and mixed methond approach (5th ed.). London: SAGE Publications.

De Vos, A. S., Strydom, H., Fouche, C. B., \& Delport, C. S. L. (2017). Research at grassroots for the social sciences and human service professional (3rd ed). Pretoria: Van Schaik.

Dimitriadou, M., Papastavrou, E., Efstathiou, G., \& Theodorou, M. (2015). Baccalaureate nursing students' perceptions of learning and supervision in the clinical environment. Nursing \& Health Sciences, 236-242. https://doi.org/10.1111/nhs. 12174

University of Namibia. (2016). Faculty board minutes. Windhoek: School of nursing.

Francis, D. (2012, December). The influence of clinical placement and experiential learning on student nurse development. The University of Adelaide, 187-200.

Government of the Republic of Namibia. (2004). Nursing Act. No 8 of 2004. Windhoek, Namibia

Green, J., \& Thorogood, N. (2018). Qualitative methods for health research (4th ed.). London: SAGE Publications. https://doi.org/10.1177/1049732318793416. https://doi.org/10.1177/1049732317746962 
Grove, S. K., Burns, N., \& Gray, J. (2013). The practice of nursing research: Appraisal, synthesis, and generation of evidence (7th ed.). Missouri: Elsevier. https://doi.org/10.12968/pnur.2013.24.1.21

Kabanya, C. N., \& Mirie, W. (2017). Determinants of satisfaction with training process among final year nursing students at Kenya Medical Training College. Journal of Scientific \& Technical Research, 1(4). https://doi.org/10.26717/BJSTR.2017.01.000331

Landers, M. G. (2018). The theory-practice gap in nursing: The role of a nurse teacher. Journal of Advanced Nursing, 32(6). https://doi.org/10.1046/j.1365-2648.2000.01605.x

Leedy, P. D., \& Ormrod, J. E. (2013). Practical research: Planning and design (8th ed.). New Jersey: Pearson Prentice-Hall.

Maree, K. (2016). First steps in research. Pretoria: Van Schaik.

Mellish, M., Brink, L., \& Paton, F. (2016). Teaching and learning the practice of nursing. Johannesburg: Heinemann.

MoHSS. (2010). Report on nurses consultative meeting. Windhoek: Ministry of Health and Social Services.

Moule, P., \& Aveyard, H. (2016). Nursing research: An introduction (3rd ed.). London: SAGE Publications.

Ngaiyaye, P. E., Bvumbwe, T., \& Chipeta, M. C. (2017). Using preceptors to improve nursing students' clinical learning outcomes: A Malawian students' perspective. International Journal of Nursing sciences, 164-165. https://doi.org/10.1016/j.ijnss.2017.03.001

Nuuyoma, V., \& Ashipala, D. O. (2018). Second year nursing students' experiences of clinical placement in a rural health center. International Journal of Studies in Nursing, 3(2), 107-111. https://doi.org/10.20849/ijsn.v3i2.417

Polit, F., \& Beck, T. (2016). Nursing research: Generating and assessing evidence for nursing practice (9th ed.). China: Lippincott Williams \& Wilkins.

Rajeswaran, L. (2016). Clinical experiences of nursing students at a selected institute of health science in Botswana. Health Science Journal, 20. https://doi.org/10.21767/1791-809X.1000471

Salifu, D. G. (2019). Experiences and perceptions of the theory-practice gap in nursing in a resource-constrained setting. Nursing Open. https://doi.org/10.1002/nop2.188

University of Namibia. (2019). Vision and mission. Retrieved 26 July 2019 from http://www.unam.edu.na/about-unam/vision-mission

Vanson, T., \& Beckett, A. (2018). Evaluation of Introduction of Nursing Associates Phase 1. Restricted External, 15.

\section{Note}

Note 1. P2G2 refers to participant and number allocated and G2 refers to group and number allocated to the group. 